\title{
Association of potential salivary biomarkers with diabetic retinopathy and its severity in type-2 diabetes mellitus: a proteomic analysis by mass spectrometry
}

Chin Soon Chee, Khai Meng Chang, Mun Fai Loke, Voon Pei Angela Loo, Visvaraja Subrayan

Aim/hypothesis The aim of our study was to characterize the human salivary proteome and determine the changes in protein expression in 2 different stages of diabetic retinopathy with type-2 diabetes mellitus: (1) with non-proliferative diabetic retinopathy (NPDR) and (2) with proliferative diabetic retinopathy (PDR). Type-2 diabetes without diabetic retinopathy (XDR) was designated as control. Method In this study, 45 saliva samples were collected (15 samples from XDR control group, 15 samples from NPDR disease group and 15 samples from PDR disease group). Salivary proteins were extracted, reduced, alkylated, trypsin digested and labeled with iTRAQ before analyzing by Orbitrap fusion tribrid mass spectrometer. Proteins annotation, fold change calculation and statistical analysis were interrogated by Proteome Discoverer. Biological pathway analysis was performed by Ingenuity Pathway Analysis. Data are available via ProteomeXchange with identifiers PXD003723-PX003725. Results A total of 315 proteins were identified from the salivary proteome and 119 proteins were found to be differentially expressed. The differentially expressed proteins from the NPDR disease group and the PDR disease group were assigned to respective canonical pathways indicating increased LXR/RXR activation, FXR/RXR activation, acute phase response signaling, sucrose degradation $V$ and regulation of actin-based motility by Rho in the PDR disease group compared to the NPDR disease group Conclusions/Interpretation Progression from non-proliferative to proliferative retinopathy in type-2 diabetic patients is a complex multi-mechanism and systemic process. Furthermore, saliva was shown to be a feasible alternative sample source for diabetic retinopathy biomarkers. 
1

2

3

4

5

6

7

8

9

10

11

12

13

14

15

16

17

18

19

20

21

22

23

24

25

26

27

28

29

30

31

32

33

34

35

36

37

38

39

40

\title{
Association of potential salivary biomarkers with diabetic retinopathy and its severity in type-2 diabetes mellitus: a proteomic analysis by mass spectrometry
}

\author{
Chin Soon Chee 1, Khai Meng Chang 1, Mun Fai Loke ${ }^{2}$, Angela Voon Pei Loo ${ }^{1 *}$, \\ Visvaraja Subrayan ${ }^{1}$
}

(1) Department of Ophthalmology, Faculty of Medicine, University of Malaya, 50603 Kuala Lumpur, Malaysia

(2) Department of Medical Microbiology, Faculty of Medicine, University of Malaya, 50603 Kuala Lumpur, Malaysia

*Corresponding author:

Angela Voon Pei Loo

Department of Ophthalmology

Faculty of Medicine

University of Malaya

50603 Kuala Lumpur

Malaysia

Phone: +603-79492060

Email: voonpei@um.edu.my 


\section{Abstract}

42

43

44

Aim/hypothesis The aim of our study was to characterize the human salivary proteome and determine the changes in protein expression in 2 different stages of diabetic retinopathy with type-2 diabetes mellitus: (1) with non-proliferative diabetic retinopathy (NPDR) and (2) with proliferative diabetic retinopathy (PDR). Type-2 diabetes without diabetic retinopathy (XDR) was designated as control.

Method In this study, 45 saliva samples were collected (15 samples from XDR control group, 15 samples from NPDR disease group and 15 samples from PDR disease group). Salivary proteins were extracted, reduced, alkylated, trypsin digested and labeled with iTRAQ before analyzing by Orbitrap fusion tribrid mass spectrometer. Proteins annotation, fold change calculation and statistical analysis were interrogated by Proteome Discoverer. Biological pathway analysis was performed by Ingenuity Pathway Analysis. Data are available via ProteomeXchange with identifiers PXD003723-PX003725.

Results A total of 315 proteins were identified from the salivary proteome and 119 proteins were found to be differentially expressed. The differentially expressed proteins from the NPDR disease group and the PDR disease group were assigned to respective canonical pathways indicating increased LXR/RXR activation, FXR/RXR activation, acute phase response signaling, sucrose degradation $\mathrm{V}$ and regulation of actin-based motility by Rho in the PDR disease group compared to the NPDR disease group

Conclusions/Interpretation Progression from non-proliferative to proliferative retinopathy in type- 2 diabetic patients is a complex multi-mechanism and systemic process. Furthermore, saliva was shown to be a feasible alternative sample source for diabetic retinopathy biomarkers.

Keywords: Diabetic retinopathy, salivary proteome, iTRAQ, LC/MS

\section{Abbreviations}

ACTB

AGC

AGE

ANXA1

APOA1

C3

CAMP

CAP1
Actin, cytoplasmic 1

Automatic gain control

Glycation end-products

Annexin A1

Apolipoprotein A-I

Complement 3

Cathelicidin antimicrobial peptide

Adenylyl cyclase-associated protein 1 


\begin{tabular}{|c|c|c|}
\hline 76 & CLU & Clusterin \\
\hline 77 & ELANE & Neutrophil elastase \\
\hline 78 & ENO1 & Alpha-enolase isoform 1 \\
\hline 79 & EZR & Ezrin \\
\hline 80 & FXR/RXR & Farnesoid X receptor/Retinoid X receptor \\
\hline 81 & GAPDH & Glyceraldehyde-3-phosphate dehydrogenase isoform 2 \\
\hline 82 & $\mathrm{GO}$ & GO annotation \\
\hline 83 & GSN & Gelsolin isoform d \\
\hline 84 & HBA1/HBA2 & Hemoglobin subunit alpha \\
\hline 85 & $\mathrm{HCD}$ & Higher-energy collisional dissociation \\
\hline 86 & HP & Haptoglobin isoform 2 \\
\hline 87 & HSPA1A/HSPA1B & Heat shock $70 \mathrm{kDa}$ protein $1 \mathrm{~A} / 1 \mathrm{~B}$ \\
\hline 88 & HSPA8 & Heat shock cognate $71 \mathrm{kDa}$ protein isoform 1 \\
\hline 89 & iBRB & Inner blood retina barrier \\
\hline 90 & IPA & Ingenuity Pathway Analysis \\
\hline 91 & iTRAQ & Isobaric tag for relative and absolute quantitation \\
\hline 92 & $\mathrm{kV}$ & kilovolt \\
\hline 93 & LC-MS & Liquid chromatography- mass spectrometer \\
\hline 94 & LCN1 & Lipocalin-1 isoform 1 \\
\hline 95 & LCN2 & Neutrophil gelatinase-associated lipocalin \\
\hline 96 & LCP1 & Plastin-2 \\
\hline 97 & LDHA & L-lactate dehydrogenase A chain isoform 3 \\
\hline 98 & LTF & lactotransferrin isoform 1 \\
\hline 99 & $\mathrm{LXR} / \mathrm{RXR}$ & Liver X receptor/ Retinoid X receptor \\
\hline 100 & MIF & Macrophage migration inhibitory factor \\
\hline 101 & MMP9 & Matrix metalloproteinase-9 \\
\hline 102 & MPO & Myeloperoxidase \\
\hline 103 & MRP8/14 & Myeloid-Related Protein-8/14 \\
\hline 104 & MS & Mass spectrometry \\
\hline 10 & NPDR & Type-2 diabetes mellitus with non-proliferative diabetic retinopathy \\
\hline
\end{tabular}


106 PDR

107 PKM

108 PLTP

109 PRDX1

110 PRTN3

111 S100A8

112 S100A9

113 SERPINA1

114 SIM

115 SLPI

116 TIMP1

117 TLR-4

118 TPM3

119 XDR

120

121

122

123

124

125

126

127

128

129

130

131

132

133

134

135

(1)

22

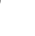

25

26

27

28

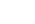

132

Type-2 diabetes mellitus with proliferative diabetic retinopathy

Pyruvate kinase isozymes M1/M2 isoform c

Phospholipid transfer protein isoform a

Peroxiredoxin-1

Profilin-1

S100 calcium-binding protein A8

S100 calcium-binding protein A9

Alpha-1-antitrypsin

Single ion monitoring

Antileukoproteinase

Metalloproteinase inhibitor 1

Toll-like receptor-4

Tropomyosin alpha-3 chain isoform

Type-2 diabetes mellitus without diabetic retinopathy 
137

138

139

140

141 


\section{Introduction}

143

144

145

146

147

148

149

150

151

152

153

154

155

156

157

158

159

160

161

162

163

164

165

166

167

168

169

170

171

172

173

174

175

176

177

178

179

180

181

182

183

184

185

Early onset of type- 2 diabetes mellitus has been devastating and a major epidemic across the world. Report shows that $7 \%$ of newly diagnosed type- 2 diabetic patients in the U.S. have been diabetic for approximately 4-7 years before diagnosis (Rao et al. 2009). There is a very low global awareness and precaution on how to prevent type- 2 diabetes. Patients with prolong type- 2 diabetes without proper consultation and medication have a higher probability of developing complications such as diabetic retinopathy which can eventually lead to blindness.

Diabetic retinopathy is one of the most common and severe microvascular complications of type-2 diabetes. Symptoms of diabetic retinopathy were retinal ischemia and increased retinal vascular permeability which leads to vision loss or blindness ultimately. Diabetic retinopathy could be classified into two main stages: non-proliferative diabetic retinopathy (NPDR) and proliferative diabetic retinopathy (PDR) in terms of the severity. The NPDR patients had lesions on the eye vasculature layer and vision would be lost if there was fluid in the central portion of the eyes (Csosz et al. 2012). PDR was literally characterized by pathological retinal vascular leakage (macular edema) and retinal neovascularization (Gao et al. 2008). There are several studies reported on the factors related to pathogenesis of PDR (Tarr et al. 2013), e.g., vascular endothelial growth factor for the proliferation and propagation of blood vessels in eyes, angiotensin-converting enzyme, insulin-like growth factor, angiopoietin, erythropoietin, placenta growth factor, advanced glycation end product, and antiangiogenic factors like pigment epithelium-derived factor.

The noninvasive nature and simple collection allows repetition and multiple collection of saliva that can potentially aid in early diagnosis, monitoring disease progression, or treatment responses with minimally trained personnel. This advantage of using saliva attracts investigators who are looking for an alternative body fluid to simplify diagnostic procedures (Giusti et al. 2007a; 2007b; Hu et al. 2007a; Peluso et al. 2007). Secretions from salivary glands, oral mucosa, periodontium, and oral microbiota all contribute to the final content of saliva. Saliva, a complex balance from local and systemic sources, allows for applications in the diagnosis not only for salivary gland disorders but also for oral diseases and systemic conditions (Caporossi et al. 2010; Good et al. 2007; Hu et al. 2007b; Lee et al. 2009). In our study, saliva samples from XDR, NPDR and PDR patient groups are selected as a diagnostic fluid to study the salivary proteome. Saliva offers several advantages over vitreous humor, tears and serum. The availability of saliva make it the simplest and non-invasive way of body fluid collection allowing repetitive collection. Saliva collection decreases the risk of contracting infectious diseases compared to other body fluids collection and it is convenient to obtain saliva from children or handicapped patients, in whom blood sampling could be inconvenient. Saliva is an ideal body fluid for the purpose of biomarker identification based on several decent studies. Castagnora et al (Castagnola et al. 2011) reported that there was existence of specific salivary biomarkers associated with a health or disease state. In the meanwhile, Shinkai et al (Shinkai et al. 2004) also reported that there was an altered saliva composition in type- 2 diabetic patients. Hence, it is important to investigate the salivary proteome profiles for diabetic retinopathy complications. Moreover, biomarkers from salivary proteome of diabetic retinopathy are yet to be discovered.

In recent years, advancement in proteomic technology has invented plenty of instruments for proteomics research. A sophisticated mass spectrometer, the Orbitrap fusion tribrid mass spectrometer is used in our study to achieve our objective. The Orbitrap fusion tribrid mass 
186

187

188

189

190

191

192

193

194

195

196

197

198

199

200

201

202

203

204

205

206

207

208

209

210

211

212

213

214

215

216

217

218

219

220

221

222

223

224

225

226

227

228

spectrometer, comprises of a mass filter, a collision cell, a high-field Oribitrap analyzer and a dual cell linear ion trap analyzer, offers high $\mathrm{MS}^{2}$ acquisition speed of $20 \mathrm{~Hz}$ (Senko et al. 2013). We believe that this new system, with its fast scan rate, could provide more comprehensive proteome analysis within shorter time. The development of higher energy collision-induced dissociation (HCD) in the LTQ-Orbitrap has also overcome the 1/3 rule limitation that restricts the analysis of product ions with $\mathrm{m} / \mathrm{z}$ values less than $25-30 \%$ of the precursor ion in traditional ion-trap instruments (Rauniyar et al. 2014). Limitations with analyzing biological samples of complex nature, such as the salivary proteome, are the masking of low-abundance proteins by the preponderance of a small number of highly abundant salivary proteins and the high dynamic range of such proteome that precludes the use of conventional proteomic strategies (Hu et al. $2005 ; 2007 a)$. A method that has been proposed to largely overcome these deficits is isobaric labeling (iTRAQ: isobaric tags for absolute and relative quantitation) (Casado-Vela et al. 2010; Rauniyar et al. 2014). These isotope tags permit ready discrimination by mass spectrometry, thereby permitting comparative quantification to a reference sample in a multiplex manner and the examination of different samples in a single mass spectrometric analysis with good quantification precision. Hence, the ratio cutoff applied for significant protein change via the iTRAQ approach is lower than the cutoff applied for the label-free quantification approach (Rauniyar et al. 2014). This is the first attempt to analyze the salivary proteome profiles of type- 2 diabetes complicated with diabetic retinopathy using the high resolution and accurate mass Orbitrap fusion tribrid mass spectrometer.

\section{Methodology}

\section{Sample collection and processing}

Saliva sample from 45 subjects with type-2 diabetes mellitus were collected. Subjects for this study were recruited from patients who visited the Eye clinic at the University of Malaya Medical Center (UMMC) during the period between November 2013 and April 2014. Patients older than 45 years old diagnosed with type- 2 diabetes for more than 5 years with or without diabetic retinopathy were included in this study. All the patients were on oral medication for glycemic index control and /or dyslipidemia (none of them were on insulin therapy). The following patients were excluded from the study: (1) patients who had oral surgery or treatment within the past 3 months; (2) patients who had active gum bleeding; (3) patients with dry mouth (e.g. Sjögren's syndrome); (4) patients who had recent oral injury; (5)patients with history of malignancy, autoimmune diseases, Hepatitis/ HIV infection; (6) patients on any types of eye drops for active eye disease (e.g. glaucoma, conjunctivitis); (7) patients who had significant ocular medium opacities such as cataract or hazy cornea; (8) patients who had intravitreal injection and/or retinal laser treatment prior to diagnose for diabetic retinopathy; (9) patients with quiescent PDR and (10) smokers. Patients were classified by their severity of diabetic retinopathy according to the International Clinical Classification System for Diabetic

Retinopathy and Diabetic Macular Edema by American Academy of Ophthalmology (Wilkinson et al. 2003). Diabetic retinopathy was graded through clinical fundus examination photography by two independent eye specialists. Subjects were grouped into three groups based on their clinical presentation: (1) type-2 diabetes without diabetic retinopathy (XDR) as control, (2) type2 diabetes with non-proliferative diabetic retinopathy (NPDR) and (3) type-2 diabetes with 
229

proliferative diabetic retinopathy (PDR) (Table 1). PDR patients with active neovascularization were included.

Subjects fasted overnight for at least 8 hours (except for drinking) prior to the collection of saliva samples. They were instructed to avoid drinks containing caffeine and alcohol for 12 hours and avoid vigorous physical activity for 4 hours prior to sample collection. In addition, they were also reminded to avoid brushing teeth 1 hour prior to sample collection and avoid applying lipstick. Saliva samples were collected between 9-10 a.m. The subjects were asked to rinse their mouths thoroughly with sterile water 10 minutes before sample collection, then to tilt their heads forward and allow saliva to flow into a sterile centrifuge tube until $5 \mathrm{~mL}$ of saliva was collected. Saliva samples were spun at $8000 \times \mathrm{g}$ for $20 \mathrm{~min}$ at $4{ }^{\circ} \mathrm{C}$ to spin down nuclei, cell debris and bacteria cells. The supernatant was then kept at $-20{ }^{\circ} \mathrm{C}$ for subsequent analysis.

This study was approved by the Medical Ethics Committee of UMMC (Reference number: 1017.28) and written informed consent was obtained from the patients prior to samples collection.

\section{Table 1 Demographic of subjects.}

\section{Proteins extraction}

Salivary protein was extracted by acetone precipitation method as described by Vitorino et al (Vitorino et al. 2012) with modification. Saliva samples were precipitated by mixing with six volumes of pre-chilled acetone (Grade AR) (Friedemann Schmidt, Parkwood, Perth, Australia) and mixed by vortexing. Each sample was allowed to stand overnight at $4{ }^{\circ} \mathrm{C}$. After incubation, all samples were centrifuged at $12000 \times \mathrm{g}$ for $30 \mathrm{~min}$. The supernatant and pellet were separated. The pellet was dried at room temperature.

\section{Protein concentration}

Protein concentration was determined using Bradford assay (Bio-Rad, Hercules, California USA) with bovine serum albumin (BSA) as standard (Bradford 1976). Protein standards and tests were prepared in triplicate.

\section{Reduction, alkylation and trypsin digestion of salivary proteins}

Reduction, alkylation and trypsin digestion of salivary proteins were carried out according to the method described by Ross et al (Ross et al. 2004) with modification. Briefly, $50 \mu \mathrm{g}$ of salivary protein was suspended in $100 \mathrm{mmol} / 1$ triethylammonium bicarbonate ( $\mathrm{pH} \mathrm{8.5)} \mathrm{(Sigma-Aldrich,}$ St. Louis, Missouri, USA) and vortex to make sure the pellet was completely dissolved. Protein reduction was carried out by adding $10 \mathrm{mmol} / 1$ tris-(2-carboxyethyl)-phosphine (Sigma-Aldrich, St. Louis, Missouri, USA) and incubated at $60{ }^{\circ} \mathrm{C}$ for $60 \mathrm{~min}$. Reduced protein was subsequently alkylated with $20 \mathrm{mmol} / 1$ iodoacetamide (Bio-Rad, Hercules, California, USA) in the dark for 60 
266

302 303

min at room temperature. Finally, the protein samples were digested with $1 \mu \mathrm{g}$ of mass spectrometry grade porcine trypsin (Calbiochem, La Jolla, California, USA) at $37^{\circ} \mathrm{C}$ for $16-18$ hours. The reaction was terminated by adding trifluoroacetic acid (Sigma-Aldrich, St. Louis, Missouri, USA) to the final concentration of $5 \%(\mathrm{v} / \mathrm{v})$.

\section{Isobaric tag for relative and absolute quantitation (iTRAQ) labeling of salivary peptides}

Digested peptides samples were labeled using the iTRAQ 8Plex Multiplexing kit (AB Sciex, Foster city, California, USA) according to the manufacturer's protocol. Peptides from XDR, NPDR and PDR patient groups were labeled with isobaric tags 113,114 and 115 respectively at room temperature for 4 hours. The reaction was quenched with $20 \mathrm{mmol} / \mathrm{l}$ Tris (pH 8.0) (SigmaAldrich, St. Louis, Missouri, USA). The contents of each iTRAQ reagent labeled sample tubes were combined.

\section{Peptide purification and concentration}

Pierce C18 Spin Column (Thermo Scientific, Rockford, Illinois, USA) was used to purify and concentrate the labeled peptides according to the manufacturer's protocol.

\section{Liquid chromatography-mass spectrometer (LC-MS) analysis}

Ten micrograms of salivary digest were separated on the EASY-nLC 1000 (Thermo Scientific, San Jose, California, USA) using the Acclaim PepMap $\mathrm{C}_{18}(3 \mu \mathrm{m}, 75 \mu \mathrm{m}$ x $50 \mathrm{~cm})$ column (Thermo Scientific, San Jose, California, USA). Solvent A was HPLC-grade water with 0.1\% (v/v) formic acid, and solvent B was HPLC grade acetonitrile with $0.1 \%$ (v/v) formic acid. Separation was performed with stepwise gradient (5-30\% B for $185 \mathrm{~min}, 30-50 \%$ B for $20 \mathrm{~min}$, $50-95 \%$ B for $20 \mathrm{~min}$ ) at $300 \mathrm{nl} / \mathrm{min}$ over $225 \mathrm{~min}$. MS data was generated using an Orbitrap fusion tribrid mass spectrometer (Thermo Scientific, San Jose, California, USA) operated with $2.5 \mathrm{kV}$ (positive ions) applied to the central electrode. The mixture of isotopolog peptides were analyzed by combining scan events from two SIM modes. The first full time scan mode (MS) employed a scan range $(\mathrm{m} / \mathrm{z})$ of 380-2,000, Orbitrap resolution of 120,000, target automatic gain control (AGC) values of 200,000 and a maximum injection time of 50 milisec. The second scan mode, HCD (high energy collisional dissociation)-MS/MS was performed at the Quadrupole with the isolation width of $1.6 \mathrm{Th}$, HCD fragmentation with normalized collision energy of $35 \%$, Orbitrap resolution of 30,000, target AGC values of 50,000, and a maximum injection time of 60 milisec. Only precursors with charge state 2-7 were subjected to $\mathrm{MS}^{2}$. Monoisotopic precursor selection and dynamic exclusion (70 sec duration, $10 \mathrm{ppm}$ mass tolerance) were enabled. Analysis was carried out with 3 technical replications.

\section{Data analysis}


304

305

306

307

308

309

310

311

312

313

314

315

316

317

318

319

320

321

322

323

324

325

326

327

328

329

330

331

332

333

334

335

336

337

338

339

340

341

342

343

The raw data was processed using Proteome Discoverer version 1.4 (Thermo Scientific, San Jose, California, USA). MS/MS spectra were searched with Sequest engine against Homo sapiens database using the following parameters: full trypsin digest with maximum 2 missed cleavages, fixed modification carbamidomethylation of cysteine $(+57.021 \mathrm{Da})$, variable modification oxidation of methionine (+15.995 Da) and iTRAQ 8-plex modification of lysine and peptide $\mathrm{N}$ termini $(+304.205 \mathrm{Da})$. Precursor mass tolerance was $10 \mathrm{ppm}$ and product ions fragment ion tolerance was $0.02 \mathrm{Da}$. Peptide spectral matches were validated using percolator based on qvalues at a $1 \%$ false discovery rate. iTRAQ ratio reporting was pair wise: NPDR/XDR (114/113) and PDR/XDR (115/113).

\section{Bioinformatic analysis of differential expressed proteins.}

Differentially expressed proteins from NPDR and PDR patient groups were further analyzed using Ingenuity Pathway Analysis (IPA version 8.8) (Qiagen, Redwood, California, USA) to statistically determine the functions and pathways associated with each of the individual proteins. Accession number for each of the proteins and the fold change between NPDR and PDR groups relative to XDR group were tabulated. IPA utilized the Ingenuity Pathways Analysis Knowledge Base (IPA KB), a manually curated database of protein interactions from the literature, for analysis. A fold change cut-off of 1.5 was set to identify significant differentially regulated proteins. A list of networks and functional and canonical pathways were generated and the significance of the associations was assessed with the Fisher's exact test $(\mathrm{p}<0.05)$.

The mass spectrometry proteomics data have been deposited to the ProteomeXchange Consortium via the PRIDE (Vizcaíno et al. 2016) partner repository with the dataset identifier sPXD003723- PXD003725.

\section{RESULT}

Based on the criteria that at least one unique peptide and a minimum of two peptides match for protein identification, 315 proteins could be identified from the salivary proteome. The mean percentage of peptide coverage was $35.17 \% \pm 2.55$ ranging from $1.72 \%$ to $87.67 \%$. The overall salivary proteome was annotated using GO annotation analysis facilitated by Proteome Discoverer version 1.4 and ProteinCenter database. Salivary proteins were assigned according to three different classifications: cellular component classification, biological process classification and molecular function classification. Of which, 19\% were cytoplasmic proteins, 19\% were extracellular proteins, $12 \%$ were membrane proteins and $11 \%$ were proteins localized in the nucleus (Figure A in S1 figure). Metabolic proteins comprised 15\% of the proteins identified, 13\% were involved in regulation of biological process and $12 \%$ were proteins that respond to stimulus (Figure B in S1 figure). As high as $29 \%$ of the proteins were involved in protein binding, $18 \%$ showed catalytic activities and 11\% was involved in metal ion binding (Figure $\mathrm{C}$ in $\mathrm{S} 1$ figure). 
For quantitative analysis, only proteins with complete labeled peptides were considered. iTRAQ data was expressed in pair ratio: NPDR vs XDR (iTRAQ 114/ iTRAQ 113) and PDR vs. XDR (iTRAQ 115/ iTRAQ 113). Only those with fold-change $<0.5$ or $>2$ were considered to be differentially expressed. A total of 119 proteins were found to be differentially expressed. Fig. 1 illustrates the comparison of the log ratio of the relative intensity (NPDR/XDR; PDR/XDR) for proteins commonly found in XDR, NPDR and PDR disease groups. Fig. 2 presents the comparison of the log ratio of the relative intensity (NPDR/XDR; PDR/XDR) for proteins unique to XDR and NPDR or PDR disease groups. Among those that are differentially expressed, 1 protein was un-regulated in NPDR and PDR compared to XDR disease groups. Eighty-two proteins were increased in PDR compared to XDR disease groups but decreased in NPDR in comparison to XDR disease groups. Two proteins were down-regulated in NPDR compared to XDR disease groups but not detected in PDR disease group. The remaining 34 proteins were increased in PDR relative to XDR disease groups but not found in NPDR disease group.

\section{Fig. 1 Log ratio of relative intensity (NPDR/XDR; PDR/XDR) for proteins commonly found in XDR, NPDR and PDR disease groups.}

\section{Fig. 2 Log ratio of relative intensity (NPDR/XDR; PDR/XDR or proteins found exclusively in NPDR and PDR disease groups.}

A total of 117 salivary proteins were increased in PDR disease group relative to XDR disease group. Eighty two increased salivary proteins in PDR disease group were decreased in NPDR disease group, 34 were not found in NPDR disease group and metalloproteinase inhibitor 1 precursor was increased in both PDR and NPDR disease groups. Table S1 lists the top 26 most up-regulated salivary proteins with a minimum fold change of 20 by relative protein abundance. Among the top 20 proteins that were increased in PDR disease group, 13\% were predicted to respond to stimulus, $10 \%$ were predicted to regulate biological process, $9 \%$ were involved in metabolism, $8 \%$ were involved in cell organization and biogenesis and $8 \%$ were predicted to be involved in defense response (Figure B in S2 figure). Most of these proteins were predicted to have protein binding capability $(28 \%)$ and $17 \%$ might have catalytic activity (Figure $\mathrm{C}$ in S2 figure). On the other hand, peroxiredoxin- 1 and unconventional myosin-IXb isoform 2 were decreased in NPDR disease group (Table S2).

Twenty one interacting proteins and 1 highly increased protein (clusterin from NPDR disease group), together with 35 interacting proteins and 1 highly increased protein (tropomyosin alpha-3 chain isoform 2 from PDR disease group) (Table in S3 table) generated 3 protein-protein networks (Figure in S3 figure). Network (A) includes the diseases and functions of connective tissue disorders, immunological disease and inflammatory disease. Network (B) includes the diseases and functions of cellular movement, hematological system development and function and immune cell trafficking while Network (C) includes the diseases and functions of cellular growth and proliferation, cancer and carbohydrate metabolism. The top three canonical pathways with the highest - log ( $p$-value) for NPDR disease group were LXR/RXR activation, glycolysis I and clathrin-mediated endocytosis signaling while for PDR group the pathways were LXR/RXR activation, glycolysis I and FXR/RXR activation. Comparison between the differentially 
390

391

392

393

394

395

396

397

398

399

400

401

402

403

404

405

406

407

408

409

410

411

412

413

414

415

416

417

418

419

420

421

422

423

424

425

426

427

428

429

430

431

expressed proteins from NPDR and PDR disease groups in different canonical pathways indicated increased LXR/RXR activation, FXR/RXR activation, acute phase response signaling, sucrose degradation $\mathrm{V}$ and regulation of actin-based motility by Rho in PDR disease group compared to NPDR disease group (Fig 3).

Fig. 3 Canonical pathways comparative studies in differentially expressed proteins from NPDR and PDR groups.

\section{Discussion}

To the best of our knowledge, the salivary proteome of diabetic retinopathy has not yet been characterized. Among top increased proteins in the PDR group, $8 \%$ were predicted to be defense proteins and $9 \%$ were metabolic proteins suggesting that the expression of salivary defense and metabolic proteins is related to diabetic retinopathy. This is consistent with the report by Fernandez-Real and Pickup (Fernandez-Real \& Pickup 2008) that defense response proteins were elevated in type-2 diabetic patients and this gradually led to surging of metabolic proteins. Most of these defense response proteins that were increased in PDR are involved with proinflammatory immune response and many had previously been reported to be associated with diabetes mellitus. Such defense response proteins include S100-A9 (Cabras et al. 2010), alpha-2macroglobulin-like protein 1 (James et al. 1980), neutrophil elastase (Collier et al. 1989), alpha1-antitrypsin (SERPINA1) (Kalis et al. 2010), cystatin-C (Reutens et al. 2013) and macrophage migration inhibitory factor (MIF) ( Tashimo et al. 2004). Heterodimer of S100-A9 and S100-A8 known as myeloid-related protein-8/14 (MRP8/14) binds to receptor for advanced glycation endproducts and Toll-like receptor-4 (TLR-4) thereby initiating the intracellular inflammatory signaling cascade (Caseiro et al. 2013). Alpha 2-macroglobulin has been suggested to be a potential biomarker for diabetic retinopathy and other diabetic complications (Lu et al. 2013). Neutrophil elastase was reported to be a marker for the development of diabetic angiopathy (Piwowar et al. 2000). Neutrophil releases neutrophil elastase that enhances inflammatory responses. Alpha-1-antitrypsin (SERPINA1) can suppress apoptosis of pancreatic $\beta$-cells that promote insulin secretion (Kalis et al. 2010). A novel immune system regulatory pathway involving SERPINA1 and complement 3 (C3) was unveiled recently (Sahu \& Lambris 2001). Activation of $\mathrm{C} 3$ promotes phagocytosis, supports local inflammatory responses against pathogens and initiates the humoral immune response; on the other hand, its activation leads to host cell damage. However, binding of SERPINA1 to C3 inhibits and regulates the cleavage and activation of $\mathrm{C} 3$ during inflammation. MIF produce by $\mathrm{T}$ lymphocytes and macrophage can initiate local inflammation through the inhibition of the random movement of macrophage and enhance their adhesion (Mitamura et al. 2000). Capillary occlusion can be caused by the natural tendency of leucocytes and macrophages to adhere to endothelium that eventually results in retinal ischemia seen in diabetic retinopathy (Schroder et al. 1991). MIF may play a role during the proliferative phase of diabetic retinopathy by activating and retaining intraocular macrophage. Furthermore, MIF interacts with peroxiredoxin-1 by reducing tautomerase and oxidoreductase activities of MIF and inhibits the activity of peroxiredoxin-1 (Kudrin \& Ray 2008). Our result show that peroxiredoxin-1 was decreased in NPDR and not found in PDR that was in line with the result reported by Rao et al (Rao et al. 2009). 
432

433

434

435

436

437

438

439

440

441

442

443

444

445

446

447

448

449

450

451

452

453

454

455

456

457

458

459

460

461

462

463

464

465

466

467

468

469

470

471

472

473

474

475

The up-regulation of BPI fold-containing family A member 1/2, BPI fold-containing family B member 2 and neutrophil gelatinase-associated lipocalin in the PDR patient group suggested that innate immune response might also be involved in PDR. This might also suggest the involvement of microbial agents in PDR pathogenesis. Binding of BPI to endotoxin of Gramnegative bacteria outer membrane could trigger sub-lethal and lethal effects on the bacteria and neutralize the activity of endotoxin (Schultz et al. 2007). Myeloperoxidase (MPO) and lactotransferrin isoform 1 (LTF) are abundantly expressed in neutrophil granulocytes with antioxidant, anticarcinogenic, antibacterial effects, implying an important role in innate immunity. During the oxidative burst of activated neutrophils, MPO utilize hydrogen peroxide and chloride anion to generate a highly reactive and cytotoxic product, hydrochlorous acid which are used by bactericidal (Mutze et al. 2003). Protein-protein networks analysis revealed that cellular target of LTF is MPO, to which LTF bind and inhibit MPO. Neutrophil gelatinaseassociated lipocalin was demonstrated to be an early biomarker for diabetic nephropathy (Bolignano et al. 2009). In addition, neutrophil gelatinase-associated lipocalin is an iron-binding protein that may inhibit the growth of bacteria by depleting the iron source of bacteria (Cherayil 2011).

In addition, neutrophil gelatinase-associated lipocalin can also activate pro matrix metalloproteinase-9 (MMP-9) (Tschesche et al. 2001). Hyperglycemia-induced activation of MMP-9 promotes apoptosis of retinal capillary cells and can result in development of diabetic retinopathy (Kowluru 2010). Interestingly, metalloproteinase inhibitor 1, an inhibitor of MMP-9, was found to be increased in both NPDR and PDR patients. In contrast, MMP-9 was low in XDR patients. Florys et al (Florys et al. 2006) reported that high blood glucose concentration could induce the expression of metalloproteinase inhibitor 1 . Thus, our results suggest that metalloproteinase inhibitor 1 may influence the development of diabetic retinopathy and combined with high levels of MMP-9 may drive the progression towards the proliferative phase.

The retina is rich in unsaturated fatty acid, rapid oxygen uptake and glucose oxidation rate compared to other areas of the human body that renders the retina highly susceptible to oxidative stress. Heme is highly toxic due to its ability to cause protein aggregation and produce lipid peroxide from lipid peroxidation that could contribute to oxidative stress. Hemopexin functions as a scavenger of heme. The finding of high level of hemopexin in the saliva of PDR patients supported the hypothesis that hyperglycemia, changes in the redox homeostasis and oxidative stress are key pathogenic events in diabetic retinopathy (Kowluru \& Chan 2007). Glycation end-products (AGEs) are produced by non-enzymatic glycation reactions of amino groups, lipids and DNA with glucose and its formation is an important pathogenic mechanism in diabetic retinopathy. AGEs have been linked to the breakdown of the inner blood retina barrier (iBRB) during diabetic retinopathy by modulating the expression of vasopermeability factor (Amin et al. 1997). Galectin-3-binding protein, an AGE-binding protein, can enhance the iBRB dysfunction in diabetes and play a significant role in AGE-related pathophysiology during diabetic retinopathy (Pugliese et al. 2000). Galectin-3-binding protein was also presented in relatively high abundance in PDR patients. High abundance of clusterin has been reported in vitreous humor of PDR patients (Gao et al. 2008). Thus, it is not surprising that our data also shows an unprecedented high abundance of clusterin in the saliva of PDR patients. Clusterin is believed to promote angiogenesis or vascular permeability, which contributes to the pathogenesis of diabetic retinopathy (Wang et al. 2013). 
Glyceraldehyde-3-phosphate dehydrogenase (GAPDH), alpha-enolase isoform 1 (ENO1) and pyruvate kinase isozymes M1/M2 isoform c (PKM) are typical enzymes found in saliva that are involved in glycolysis and gluconeogenesis. Although GAPDH is a glycolytic enzyme, it has also been proven to have multiple cytoplasmic, membrane, and nuclear functions. Saunders et al (Saunders et al. 1997) reported that GAPDH was a major intracellular messenger mediating apoptosis of cells and GAPDH translocation to the nucleus was considered a crucial step in glucose-induced apoptosis of retinal Muller cells. Moreover, the role of GADPH in the development and progression of diabetic retinopathy has been investigated by Kanwar \& Kowluru (Kanwar \& Kowluru 2009).

LXR/RXR activation, FXR/RXR activation, clathrin-mediated endocytosis signaling, acute phase response signaling and regulation of actin-based motility by Rho are highly associated with the pathogenesis and progression of diabetic retinopathy. Activation of liver X receptor (LXR) promotes reverse cholesterol transport and suppressed inflammatory response which in turn improve and inhibit the progression of diabetic retinopathy (Hazra et al. 2012). Retinoid X receptor ( $\mathrm{RXR}$ ) is known to be associated with the progression of diabetic retinopathy (Roy et al. 2009), with RXR activation playing a key role in inhibiting high-glucoseinduced oxidative stress, systemic lipid and glucose metabolism, energy homeostasis, and inflammatory control. Role of farnesoid X receptor (FXR) in relation to diabetic retinopathy had not been reported so far, however, the role of FXR in diabetic nephropathy (Wang et al. 2010) and atherosclerotic lesion formation (Hartman et al. 2009) were well established. FXR is involved in microvascular or macrovascular complication of diabetes; hence, FXR may be related to the pathogenesis of diabetic retinopathy. Clathrin-mediated endocytosis is involved in the internalization of the ligand-receptor complex through clathrin-coated vesicles that initialize the intracellular signal transduction cascade in response to the stimulus. AGEs are known to accumulate within the neural retina of diabetics but the effect on neural dysfunction and depletion during retinopathy was poorly investigated (Stitt 2003). Retinal microvascular endothelial cells express AGE-receptor and mediate endocytic uptake of AGEs eventually leads to increased retinal vascular cells toxicity, affecting capillary function (Stitt 2003). Mizuno et al (Mizuno et al. 2010) reported that cellular degeneration, remodeling and cell death leading to emerging of new blood vessels which was observed in PDR was the consequence of excessive glutamate up-take by retinal vascular endothelial cells. As expected, acute phase response signaling pathway had played a causative role in the pathogenesis of diabetic retinopathy. Acute phase response is generally considered an adaptive response that restores homeostasis. However, excessive or persistent overexpression of acute-phase proteins can lead to tissue and organ damage (Gerhardinger et al. 2005). GTPases of the Rho family regulate the interaction between cells and extracellular matrix resulting in angiogenesis, vascular permeability, leukocyte migration and platelet formation in vivo In the early stage of angiogenesis, GTPase Rho facilitates the endothelial cell retraction and release of junctional complex simultaneously further facilitating the vascular leakage (Cheresh \& Stupack 2008). Neovasculation is the main event in the proliferative stage of diabetic retinopathy and GTPase Rho may be a key regulator enzyme in the early stage of angiogenesis. Comparing this profile of vitreous (Gao et al. 2008; Wang et al. 2013; Yamane et al. 2003; Yu et al. 2008), similarities were noted in Table 2. This demonstrates that local (vitreous) changes in protein levels associated with pathogenesis and progression of diabetic retinopathy may be reflected systemically in the saliva. 
520

521

522

523

524

525

526

527

528

529

530

531

532

533

534

535

536

\section{Acknowledgement}

538

539

540

541

542 inflammation. analysis.
As other microvascular complications of diabetes also progress with inflammatory processes, serum creatinine was measured (Table 1) to exclude patients with severe diabetic nephropathy. However, patients with non-detectable microvascular complications were not excluded, which is a limitation of our study. Furthermore, although patients with detectable poor oral hygiene were excluded, it is not possible to rule out patients with mild salivary gland

In conclusion, the progression from non-proliferative to proliferative retinopathy in type2 diabetic patients is a complex multi-mechanism and systemic process (Fig 4). These proteins may also be potential salivary biomarkers that correlate with progressive stages of diabetic retinopathy. Thus, saliva may be a convenient and less invasive alternative sample to vitreous humor, tear and serum for diabetic retinopathy protein biomarker development.

Table 2 Proteins associated with NPDR and PDR that were reported in vitreous.

Fig. 4 Summary of pathogenetic mechanism for non-proliferative diabetic retinopathy and proliferative diabetic retinopathy and the functional pathways involved.

The authors would like to thank Mr. HT Cheah (Engineer of Orbitrap fusion tribrid mass spectrometer) for his technical assistance with mass spectrometer setting, optimization, and data 


\section{References}

544

545

546

547

548

549

550

551

552

553

554

555

556

557

558

559

560

561

562

563

564

565

566

567

568

569

570

571

572

573

574

575

576

577

578

579

580

581

582

583

584

585

586

587

Amin RH, Frank RN, Kennedy A, Eliott D, Puklin JE, Abrams GW. 1997. Vascular endothelial growth factor is present in glial cells of the retina and optic nerve of human subjects with nonproliferative diabetic retinopathy. Investigative Ophthalmology \& Visual Science 38(1):36-47.

Bolignano D, Lacquaniti A, Coppolino G, Donato V, Fazio MR, Nicocia G, Buemi M. 2009. Neutrophil Gelatinase-Associated Lipocalin as an Early Biomarker of Nephropathy in Diabetic Patients. Kidney \& Blood Pressure Research 32(2):91-98. doi: 10.1159/000209379.

Bradford MM. 1976. A rapid and sensitive method for the quantitation of microgram quantities of protein utilizing the principle of protein-dye binding. Analytical Biochemistry 72:248-254.

Cabras T, Pisano E, Mastinu A, Denotti G, Pusceddu PP, Inzitari R, Fanali C, Nemolato S, Castagnola M, Messana I. 2010. Alterations of the Salivary Secretory Peptidome Profile in Children Affected by Type 1 Diabetes. Molecular \& Cellular Proteomics 9(10):2099-2108. doi: 10.1074/mcp.M110.001057.

Caporossi L, Santoro A, Papaleo B. 2010. Saliva as an analytical matrix: state of the art and application for biomonitoring. Biomarkers 15(6):475-487. doi: 10.3109/1354750X.2010.481364.

Casado-Vela J, Martínez-Esteso MJ, Rodriguez E, Borrás E, Elortza F, Bru-Martínez R. 2010. iTRAQ-based quantitative analysis of protein mixtures with large fold change and dynamic range. Proteomics 10(2):343-347. doi: 10.1002/pmic.200900509.

Caseiro A, Ferreira R, Padrao A, Quintaneiro C, Pereira A, Marinheiro R, Vitorino R, Amado F. 2013. Salivary proteome and peptidome profiling in type 1 diabetes mellitus using a quantitative approach. Journal of Proteome Research 12(4):1700-1709. doi: 10.1021/pr3010343.

Castagnola M, Picciotti PM, Messana I, Fanali C, Fiorita A, Cabras T, Calo L, Pisano E, Passali GC, lavarone F, Paludetti G, Scarano E. 2011. Potential applications of human saliva as diagnostic fluid. Acta Otorhinolaryngologica Italica 31(6):347-357.

Cherayil BJ. 2011. The role of iron in the immune response to bacterial infection. Immunologic Research 50(1):1-9. doi: 10.1007/s12026-010-8199-1.

Cheresh DA, Stupack DG. 2008. Regulation of angiogenesis: apoptotic cues from the ECM. Oncogene 27(48):6285-6298. doi: 10.1038/onc.2008.304.

Collier A, Jackson M, Bell D, Patrick AW, Matthews DM, Young RJ, Clarke BF, Dawes J. 1989. Neutrophil Activation Detected by Increased Neutrophil Elastase Activity in Type-1 (Insulin-Dependent) Diabetes-Mellitus. Diabetes Research Clinical and Experimental 10(3):135-138.

Csosz E, Boross P, Csutak A, Berta A, Toth F, Poliska S, Torok Z, Tozser J. 2012. Quantitative analysis of proteins in the tear fluid of patients with diabetic retinopathy. Journal of Proteomics 75(7):21962204. doi: 10.1016/j.jprot.2012.01.019.

Fernández -Real JM, Pickup JC. 2008. Innate immunity, insulin resistance and type 2 diabetes. Trends in Endocrinology and Metabolism 19(1):10-16. doi: 10.1016/j.tem.2007.10.004.

Florys B, Głowińska B, Urban M, Peczyńska J. 2006. [Metalloproteinases MMP-2 and MMP-9 and their inhibitors TIMP-1 and TIMP-2 levels in children and adolescents with type 1 diabetes]. Endokrynol Diabetol Chor Przemiany Materii Wieku Rozw 12:(3)184-189.

Gao BB, Chen XH, Timothy N, Aiello LP, Feener EP. 2008. Characterization of the vitreous proteome in diabetes without diabetic retinopathy and diabetes with proliferative diabetic retinopathy. Journal of Proteome Research 7(6):2516-2525. doi: 10.1021/Pr800112g.

Gerhardinger C, Costa MB, Coulombe MC, Toth I, Hoehn T, Grosu P. 2005. Expression of acute-phase response proteins in retinal Muller cells in diabetes. Investigative Ophthalmology \& Visual Science 46(1):349-357. doi: 10.1167/lovs.04-0860 
588

589

590

591

592

593

594

595

596

597

598

599

600

601

602

603

604

605

606

607

608

609

610

611

612

613

614

615

616

617

618

619

620

621

622

623

624

625

626

627

628

629

630

631

632

Giusti L, Baldini C, Bazzichi L, Ciregia F, Tonazzini I, Mascia G, Giannaccini G, Bombardieri S, Lucacchini A. 2007a. Proteome analysis of whole saliva: a new tool for rheumatic diseases - the example of Sjögren's syndrome. Proteomics 7(10):1634-1643.

Giusti L, Bazzichi L, Baldini C, Ciregia F, Mascia G, Giannaccini G, Del Rosso M, Bombardieri S, Lucacchini A. 2007b. Specific proteins identified in whole saliva from patients with diffuse systemic sclerosis. The Journal of Rheumatology 34(10):2063-2069.

Good DM, Thongboonkerd V, Novak J, Bascands JL, Schanstra JP, Coon JJ, Dominiczak A, Mischak H. 2007. Body fluid proteomics for biomarker discovery: lessons from the past hold the key to success in the future. Journal of Proteome Research 6(12):4549-4555.

Hartman HB, Gardell SJ, Petucci CJ, Wang SG, Krueger JA, Evans MJ. 2009. Activation of farnesoid X receptor prevents atherosclerotic lesion formation in LDLR-/- and apoE(-/-) mice. Journal of Lipid Research 50(6):1090-1100. doi: 10.1194/jlr.M800619-JLR200.

Hazra S, Rasheed A, Bhatwadekar A, Wang XX, Shaw LC, Patel M, Caballero S, Magomedova L, Solis N, Yan YQ, Wang WD, Thinschmidt JS, Verma A, Li QH, Levi M, Cummins CL, Grant MB. 2012. Liver X Receptor Modulates Diabetic Retinopathy Outcome in a Mouse Model of StreptozotocinInduced Diabetes. Diabetes 61(12):3270-3279. doi: 10.2337/Db11-1596.

Hu S, Wang J, Meijer J, Leong S, Xie Y, Yu T, Zhou H, Henry S, Vissink A, Pijpe J, Kallenberg C, Elashoff D, Loo JA, Wong DT. 2007b. Salivary proteomic and genomic biomarkers for primary Sjögren's syndrome. Arthritis Rheumatism 56(11):3588-3600.

Hu S, Loo JA, Wong DT. 2007a. Human saliva proteome analysis and disease biomarker discovery. Expert Review of Proteomics 4(4):531-538.

Hu S, Xie Y, Ramachandran P, Ogorzalek Loo RR, Li Y, Loo JA, Wong DT. 2005. Large-scale identification of proteins in human salivary proteome by liquidchromatography/mass spectrometry and twodimensional gel electrophoresis-mass spectrometry. Proteomics 5(6):1714-1728.

James K, Merriman J, Gray RS, Duncan L, Herd R. 1980. Serum alpha 2-macroglobulin levels in diabetes. Journal of Clinical Pathology 33(2):163-166.

Kadoglou NP, Daskalopoulou SS, Perrea D, Liapis CD. 2005. Matrix metalloproteinases and diabetic vascular complications. Angiology 56(2):173-189.

Kalis M, Kumar R, Janciauskiene S, Salehi A, Cilio CM. 2010. Alpha 1-antitrypsin enhances insulin secretion and prevents cytokine-mediated apoptosis in pancreatic beta-cells. Islets 2(3):185-189. doi: 10.4161/isl.2.3.11654.

Kanwar M, Kowluru RA. 2009. Role of Glyceraldehyde 3-Phosphate Dehydrogenase in the Development and Progression of Diabetic Retinopathy. Diabetes 58(1):227-234. doi: 10.2337/Db08-1025.

Kowluru RA. 2010. Role of Matrix Metalloproteinase-9 in the Development of Diabetic Retinopathy and Its Regulation by H-Ras. Investigative Ophthalmology \& Visual Science 51(8):4320-4326. doi: 10.1167/iovs.09-4851

Kowluru RA, Chan PS. 2007. Oxidative Stress and Diabetic Retinopathy. Experimental Diabetes Research 2007:43603. doi: 10.1155/2007/43603.

Kudrin A, Ray D. 2008. Cunning factor: macrophage migration inhibitory factor as a redox-regulated target. Immunology and Cell Biology 86(3):232-238. doi: 10.1038/sj.icb.7100133.

Lee JM, Garon E, Wong DT. 2009. Salivary diagnostics. Orthodontics and Craniofacial Research 12(3):206-211. doi: 10.1111/j.1601-6343.2009.01454.x.

Lu CH, Lin ST, Chou HC, Lee YR, Chan HL. 2013. Proteomic analysis of retinopathy-related plasma biomarkers in diabetic patients. Archives of Biochemistry and Biophysics 529(2):146-156. doi: 10.1016/j.abb.2012.11.004. 
633

634

635

636

637

638

639

640

641

642

643

644

645

646

647

648

649

650

651

652

653

654

655

656

657

658

659

660

661

662

663

664

665

666

667

668

669

670

671

672

673

674

675

676

677

678

Mitamura Y, Takeuchi S, Matsuda A, Tagawa Y, Mizue Y, Nishihira J. 2000. Macrophage migration inhibitory factor levels in the vitreous of patients with proliferative diabetic retinopathy. British Journal of Ophthalmology 84(6):636-639. Doi 10.1136/Bjo.84.6.636.

Mizuno F, Barabas P, Krizaj D, Akopian A. 2010. Glutamate-induced internalization of Ca(v)1.3 L-type $\mathrm{Ca} 2+$ channels protects retinal neurons against excitotoxicity. The Journal of Physiology 588(Pt 6):953-966. doi: 10.1113/jphysiol.2009.181305.

Mütze S, Hebling U, Stremmel W, Wang J, Arnhold J, Pantopoulos K, Mueller S. 2003. Myeloperoxidasederived hypochlorous acid antagonizes the oxidative stress-mediated activation of iron regulatory protein 1. Journal of Biological Chemistry 278(42):40542-40549. doi: 10.1074/jbc.M307159200.

Peluso G, De Santis M, Inzitari R, Fanali C, Cabras T, Messana I, Castagnola M, Ferraccioli GF. 2007. Proteomic study of salivary peptides and proteins in patients with Sjögren's syndrome before and after pilocarpine treatment. Arthritis and Rheumatism. 56(7):2216-2222.

Piwowar A, Knapik-Kordecka M, Warwas M. 2000. Concentration of leukocyte elastase in plasma and polymorphonuclear neutrophil extracts in type 2 diabetes. Clinical Chemistry and Laboratory Medicine 38(12):1257-1261. doi: 10.1515/Cclm.2000.198.

Pugliese G, Pricci F, Leto G, Amadio L, lacobini C, Romeo G, Lenti L, Sale P, Gradini R, Liu FT, Di Mario U. 2000. The diabetic milieu modulates the advanced glycation end product-receptor complex in the mesangium by inducing or upregulating galectin-3 expression. Diabetes 49(7):1249-1257. doi: 10.2337/diabetes.49.7.1249.

Rao PV, Reddy AP, Lu X, Dasari S, Krishnaprasad A, Biggs E, Roberts CT, Nagalla SR. 2009. Proteomic identification of salivary biomarkers of type-2 diabetes. Journal of Proteome Research 8(1):239245. 10.1021/pr8003776

Rauniyar N, Yates JR 3rd. 2014. Isobaric labeling-based relative quantification in shotgun proteomics. Journal of Proteome Research 13(12):5293-309. doi: 10.1021/pr500880b.

Reutens AT, Bonnet F, Lantieri O, Roussel R, Balkau B, Epidemiological Study on the Insulin Resistance Syndrome Study Group. 2013. The association between cystatin $C$ and incident type 2 diabetes is related to central adiposity. Nephrology, Dialysis, Transplantation 28(7):1820-1829. doi: 10.1093/ndt/gfs561.

Ross PL, Huang YLN, Marchese JN, Williamson B, Parker K, Hattan S, Khainovski N, Pillai S, Dey S, Daniels S, Purkayastha S, Juhasz P, Martin S, Bartlet-Jones M, He F, Jacobson A, Pappin DJ. 2004. Multiplexed protein quantitation in Saccharomyces cerevisiae using amine-reactive isobaric tagging reagents. Molecular \& Cellular Proteomics 3(12):1154-1169. doi: 10.1074/mcp.M400129-MCP200.

Roy MS, Hallman M, Fu YP, Machado M, Hanis CL. 2009. Assessment of 193 Candidate Genes for Retinopathy in African Americans With Type 1 Diabetes. Archives of Ophthalmology 127(5):605612. doi: 10.1001/archophthalmol.2009.48.

Sahu A, Lambris JD. 2001. Structure and biology of complement protein C3, a connecting link between innate and acquired immunity. Immunological Reviews 180:35-48. doi: 10.1034/j.1600065X.2001.1800103.x

Saunders PA, ChaleckaFranaszek E, Chuang DM. 1997. Subcellular distribution of glyceraldehyde-3phosphate dehydrogenase in cerebellar granule cells undergoing cytosine arabinoside-induced apoptosis. Journal of Neurochemistry 69(5):1820-1828.

Schröder S, Palinski W, Schmid-Schönbein GW. 1991. Activated Monocytes and Granulocytes, Capillary Nonperfusion, and Neovascularization in Diabetic-Retinopathy. American Journal of Pathology 139(1):81-100. 
679

680

681

682

683

684

685

686

687

688

689

690

691

692

693

694

695

696

697

698

699

700

701

702

703

704

705

706

707

708

709

710

711

712

713

714

715

716

717

718

719

720

721

722

723
Schultz H, Hume J, Zhang DS, Gioannini TL, Weiss JP. 2007. A novel role for the bactericidal/permeability increasing protein in interactions of gram-negative bacterial outer membrane Blebs with dendritic cells. Journal of Immunology 179(4):2477-2484.

Senko, MW, Remes PM, Canterbury JD, Mathur R, Song Q, Eliuk SM, Mullen C, Earley L, Hardman H, Blethrow JD, Bui H, Specht A, Lange O, Denisov E, Makarov A, Horning S, Zakrouskov V. 2013. Novel parallelized quadrupole/linear ion trap/orbitrap tribrid mass spectrometer improves proteome coverage and peptide identification rates. Analytical Chemistry 85(24):11710-11714. doi: 10.1021/ac403115c.

Shinkai RSA, Cornell JE, Hatch JP, Yeh CK. 2004. Intraoral tactile sensitivity in adults with diabetes. Diabetes Care 27(4):869-873. doi: 10.2337/diacare.27.4.869.

Stitt AW. 2003. The role of advanced glycation in the pathogenesis of diabetic retinopathy. Experimental and Molecular Pathology 75(1):95-108. doi: 10.1016/S0014-4800(03)00035-2.

Tashimo A, Mitamura Y, Nagai S, Nakamura Y, Ohtsuka K, Ohtsuka K, Mizue Y, Nishihira J. 2004. Aqueous levels of macrophage migration inhibitory factor and monocyte chemotactic protein-1 in patients with diabetic retinopathy. Diabetic Medicine 21(12):1292-1297.

Tarr JM, Kaul K, Chopra M, Kohner EM, Chibber R. 2013. Pathophysiology of diabetic retinopathy. ISRN Ophthalmology 2013:343560. doi: 10.1155/2013/343560.

Tschesche H, Zolzer V, Triebel S, Bartsch S. 2001. The human neutrophil lipocalin supports the allosteric activation of matrix metalloproteinases. European Journal of Biochemistry 268(7):1918-1928. doi: 10.1046/j.1432-1327.2001.02066.x.

Vitorino R, Barros AS, Caseiro A, Ferreira R, Amado F. 2012. Evaluation of different extraction procedures for salivary peptide analysis. Talanta 94:209-215. doi: 10.1016/j.talanta.2012.03.023.

Vizcaíno JA, Csordas A, del-Toro N, Dianes JA, Griss J, Lavidas I, Mayer G, Perez-Riverol Y, Reisinger F, Ternent T, Xu QW, Wang R, Hermjakob H. 2016. 2016 update of the PRIDE database and related tools. Nucleic Acids Research 44(D1):D447-D456. doi: 10.1093/nar/gkv1145.

Wang H, Feng L, Hu JW, Xie CL, Wang F. 2013. Differentiating vitreous proteomes in proliferative diabetic retinopathy using high-performance liquid chromatography coupled to tandem mass spectrometry. Experimental Eye Research 108:110-119. doi: 10.1016/j.exer.2012.11.023.

Wang XX, Jiang T, Shen Y, Caldas Y, Miyazaki-Anzai S, Santamaria H, Urbanek C, Solis N, Scherzer P, Lewis L, Gonzalez FJ, Adorini L, Pruzanski M, Kopp JB, Verlander JW, Levi M. 2010. Diabetic Nephropathy Is Accelerated by Farnesoid X Receptor Deficiency and Inhibited by Farnesoid X Receptor Activation in a Type 1 Diabetes Model. Diabetes 59(11):2916-2927. doi: 10.2337/Db100019.

Wilkinson CP, Ferris FL, Klein RE, Lee PP, Agardh CD, Davis M, Dills D, Kampik A, Pararajasegaram R, Verdaguer JT, Global Diabetic Retinopathy Project Group. 2003. Proposed international clinical diabetic retinopathy and diabetic macular edema disease severity scales. Ophthalmology 110(9):1677-1682. doi: 10.1016/S0161-6420(03)00475-5.

Yamane K, Minamoto A, Yamashita H, Takamura H, Miyamoto-Myoken Y, Yoshizato K, Nabetani T, Tsugita A, Mishima HK. 2003. Proteome analysis of human vitreous proteins. Molecular \& Cellular Proteomics 2(11):1177-1187. doi: 10.1074/mcp.M300038-MCP200.

Yu J, Liu F, Cui SJ, Liu Y, Song ZY, Cao H, Chen FE, Wang WJ, Sun T, Wang F. 2008. Vitreous proteomic analysis of proliferative vitreoretinopathy. Proteomics 8(17):3667-3678. doi: 10.1002/pmic.200700824. 
724

725

726

727

728

729

730

731

732

733

734

735

736

737

738

739

740

741

742

743

744

745

746

747

748

749

750

751

752

753

754

755

756

757

758

759

760

\title{
Supplementary figures
}

S1 figure. Gene ontology (GO) classification of 315 salivary proteins identified in this study. The proteins were classified based on (A) subcellular localization, (B) biological processes involved and $(\mathrm{C})$ molecular functions.

S2 figure. Gene ontology (GO) classification of top 20 up-regulated salivary proteins identified in this study. The proteins were classified based on (A) subcellular localization, (B) biological processes involved and (C) molecular functions.

S3 figure. Protein-protein interaction network prediction. Network (A) contains 35 proteins involved in connective tissue disorders, immunological disease and inflammatory disease in which 22 proteins were identified from the NPDR disease group. Network (B) contains 35 proteins involved in cellular movement, hematological system development and function and immune cell trafficking in which 28 proteins are identified from the PDR disease group. Network (C) contains 26 proteins involved in cellular growth and proliferation, cancer and carbohydrate metabolism in which 10 proteins are identified in PDR disease group. (ACTB = actin, cytoplasmic 1 , ANXA1 = annexin A1, APOA1 = apolipoprotein A-I , CAMP = cathelicidin antimicrobial peptide, $\mathrm{CAP} 1=$ adenylyl cyclase-associated protein $1, \mathrm{CLU}=$ clusterin, $\mathrm{C} 3$ = complement $\mathrm{C} 3, \mathrm{ELANE}=$ neutrophil elastase, $\mathrm{ENO} 1$ = alpha-enolase isoform 1, $\mathrm{EZR}=$ ezrin, GAPDH = glyceraldehyde-3-phosphate dehydrogenase isoform 2, GSN = gelsolin isoform d, HBA1/HBA2 = hemoglobin subunit alpha, HP = haptoglobin isoform 2, HSPA8 = heat shock cognate $71 \mathrm{kDa}$ protein isoform 1 , HSPA1A/HSPA1B = heat shock $70 \mathrm{kDa}$ protein 1A/1B, LCP1 = plastin-2, , LCN1 = lipocalin-1 isoform 1, LCN2 = neutrophil gelatinaseassociated lipocalin, $\mathrm{LDHA}=\mathrm{L}-$ lactate dehydrogenase $\mathrm{A}$ chain isoform 3, LTF $=$ lactotransferrin isoform $1, \mathrm{MIF}=$ macrophage migration inhibitory factor, MMP9 = matrix metalloproteinase-9, MPO = myeloperoxidase, $\mathrm{PKM}=$ pyruvate kinase isozymes M1/M2 isoform c, PLTP $=$ phospholipid transfer protein isoform a, PRDX1 = peroxiredoxin-1, PRTN3 = profilin-1, SERPINA1 = alpha-1-antitrypsin, SLPI = antileukoproteinase, S100A8 = protein S100-A8, S100A9 = protein S100-A9, TIMP1 = metalloproteinase inhibitor 1 , TPM3 = tropomyosin alpha-3 chain isoform 2)

\section{Supplementary tables}

\author{
S1 table. Salivary proteins that are differentially expressed in PDR disease group \\ compared to XDR disease group.
}


761 S2 table. Salivary proteins that are differentially expressed in NPDR patient group

762 compared to XDR patient group.

763

764

765 S3 table The differentially expressed proteins identified from the study that interact with 766 each other in the protein-protein network analysis. 


\section{Table 1 (on next page)}

Demographic of subjects.

M, Malays; I, Indian; C, Chinese; F, Female. All the pairs were compared using one-way ANOVA and Student's t-test, there no statistically significant difference ( $p$-value all $>0.05$ ) 
1 Table 1 Demographic of subjects.

\begin{tabular}{|c|c|c|c|}
\hline Parameters & $\begin{array}{c}\text { XDR } \\
(\mathrm{N}=15)\end{array}$ & $\begin{array}{l}\text { NPDR } \\
(\mathrm{N}=15)\end{array}$ & $\begin{array}{c}\text { PDR } \\
(\mathrm{N}=15)\end{array}$ \\
\hline Age & $61.8 \pm 8.77$ & $60.63 \pm 6.49$ & $58.94 \pm 6.98$ \\
\hline Race (M/I/C) & $7 / 3 / 5$ & $7 / 5 / 3$ & $9 / 4 / 2$ \\
\hline Sex (Male/F) & $5 / 10$ & $7 / 8$ & $8 / 7$ \\
\hline Duration of diabetes (year) & $12.87 \pm 4.97$ & $13.94 \pm 7.15$ & $14.62 \pm 5.51$ \\
\hline $\mathrm{HbA}_{1 \mathrm{c}}(\%)$ & $7.73 \pm 1.15$ & $8.43 \pm 1.08$ & $8.85 \pm 1.9$ \\
\hline Fasting blood sugar (mmol/l) & $8.16 \pm 1.62$ & $8.6 \pm 3.37$ & $8.99 \pm 3.3$ \\
\hline Creatinine $(\mu \mathrm{g} / \mathrm{l})$ & $93.9 \pm 41.17$ & $107.0 \pm 40.9$ & $125.3 \pm 71.86$ \\
\hline
\end{tabular}

M, Malays; I, Indian; C, Chinese; F, Female.

All the pairs were compared using ANOVA and T-test, there no statistically significant difference $(\mathrm{p}$-value all $>0.05)$ 
Table 2 (on next page)

Proteins associated with NPDR and PDR that were reported in vitreous. 
1 Table 2 Proteins associated with NPDR and PDR that were reported in vitreous.

\begin{tabular}{|c|c|c|}
\hline Protein name & Saliva & Vitreous \\
\hline $\begin{array}{l}\text { Alpha-1-antitrypsin } \\
\text { (SERPINA1) }\end{array}$ & Elevated in PDR & $\begin{array}{l}\text { Elevated in moderate and severe PDR (Gao } \\
\text { et al. 2008; Kanwar et al. 2009; Hazra et al. } \\
\text { 2012) }\end{array}$ \\
\hline Alpha-2-macroglobulin & Elevated in PDR & $\begin{array}{l}\text { Elevated in severe PDR (Gao et al. 2008; } \\
\text { Kanwar et al. 2009; Hazra et al. 2012) }\end{array}$ \\
\hline Alpha-enolase & Elevated in PDR & $\begin{array}{l}\text { Present in control and moderate PDR } \\
\text { (Kanwar et al. 2009; Hazra et al. 2012) }\end{array}$ \\
\hline Apolipoprotein A-I & Elevated in PDR & $\begin{array}{l}\text { Elevated in moderate and severe PDR (Gao } \\
\text { et al. 2008; Kanwar et al. 2009; Hazra et al. } \\
\text { 2012) }\end{array}$ \\
\hline Catalase & Elevated in PDR & $\begin{array}{l}\text { Present in XDR and PDR (Gao et al. 2008; } \\
\text { Kanwar et al. 2009) }\end{array}$ \\
\hline Clusterin & Elevated in PDR & $\begin{array}{l}\text { Present in vitreous (esp. moderate and } \\
\text { severe PDR (Gao et al. 2008; Hazra et al. } \\
\text { 2012); decreased in PDR (Kadoglou et al. } \\
\text { 2005) }\end{array}$ \\
\hline Complement C3 & Elevated in PDR & $\begin{array}{l}\text { Elevated in moderate PDR (Gao et al. } \\
\text { 2008; Hazra et al. 2012) }\end{array}$ \\
\hline Cystatin-C & Elevated in PDR & $\begin{array}{l}\text { Present in vitreous (control, moderate and } \\
\text { severe PDR) (Gao et al. 2008; Hazra et al. } \\
\text { 2012) }\end{array}$ \\
\hline $\begin{array}{l}\text { Fructose-bisphosphate } \\
\text { aldolase C }\end{array}$ & Elevated in PDR & Present in XDR (Gao et al. 2008) \\
\hline Galectin-3-binding protein & Elevated in PDR & $\begin{array}{l}\text { Elevated in severe PDR (Gao et al. 2008; } \\
\text { Hazra et al. 2012) }\end{array}$ \\
\hline Gelsolin & Elevated in PDR & $\begin{array}{l}\text { Present in moderate and severe PDR } \\
\text { (Hazra et al. 2012) }\end{array}$ \\
\hline $\begin{array}{l}\text { Glyceraldehyde-3-phosphate } \\
\text { dehydrogenase }\end{array}$ & Elevated in PDR & $\begin{array}{l}\text { Decreased in PDR (Kadoglou et al. 2005); } \\
\text { present in control and moderate PDR } \\
\text { (Hazra et al. 2012) }\end{array}$ \\
\hline Haptoglobin & Elevated in PDR & $\begin{array}{l}\text { Present in vitreous (esp. severe PDR) (Gao } \\
\text { et al. 2008; Kanwar et al. 2009; Hazra et al. } \\
\text { 2012) }\end{array}$ \\
\hline Hemoglobulin subunit alpha & Elevated in PDR & Elevated in PDR (Gao et al. 2008) \\
\hline Hemopexin & Elevated in PDR & $\begin{array}{l}\text { Elevated in XDR (Gao et al. 2008; } \\
\text { Kadoglou et al. 2005),32]; present in } \\
\text { control, moderate and severe PDR (Kanwar } \\
\text { et al. 2009; Hazra et al. 2012) }\end{array}$ \\
\hline Peroxiredoxin-1 & $\begin{array}{l}\text { Decreased in } \\
\text { NPDR }\end{array}$ & $\begin{array}{l}\text { Elevated in PDR (Gao et al. 2008); present } \\
\text { in control (Hazra et al. 2012) }\end{array}$ \\
\hline Protein S100-A8 & Elevated in PDR & Present in XDR and PDR (Gao et al. 2008) \\
\hline Protein S100-A9 & Elevated in PDR & Present in XDR and PDR (Gao et al. 2008) \\
\hline
\end{tabular}


1

Log ratio of relative intensity (NPDR/XDR; PDR/XDR) for proteins commonly found in $X D R, N P D R$ and PDR disease groups. 
keratin, type II cytoskeletal 6A [Homo sapiens] histone H2A type 3 [Homo sapiens] histone $\mathrm{H} 2 \mathrm{~A}$ type 2-C [Homo sapiens] alpha-amylase $2 \mathrm{~B}$ precursor [Homo sapiens] suprabasin isoform 1 precursor [Homo sapiens] TMEM189-UBE2V1 fusion protein [Homo sapiens] actin, alpha skeletal muscle [Homo sapiens] keratin, type II cytoskeletal 5 [Homo sapiens] proline-rich protein 4 isoform 2 precursor [Homo sapiens] ubiquitin-60S ribosomal protein $L 40$ precursor [Homo sapiens] alpha-1-acid glycoprotein 2 precursor [Homo sapiens] neutrophil defensin 1 preproprotein [Homo sapiens] metalloproteinase inhibitor 1 precursor [Homo sapiens] hemoglobin subunit alpha [Homo sapiens] glyceraldehyde-3-phosphate dehydrogenase isoform 2 [Homo sapiens] phosphoglycerate mutase 1 [Homo sapiens] pyruvate kinase isozymes M1/M2 isoform c [Homo sapiens] cystatin-S precursor [Homo sapiens] UPF0762 protein C6orf58 precursor [Homo sapiens] cystatin-B [Homo sapiens] cystatin-SN precursor [Homo sapiens] apolipoprotein A-I preproprotein [Homo sapiens] glutathione S-transferase P [Homo sapiens] cystatin-SA precursor [Homo sapiens] serpin B3 [Homo sapiens]

fructose-bisphosphate aldolase A isoform 2 [Homo sapiens] hemoglobin subunit beta [Homo sapiens] protein S100-A8 [Homo sapiens] actin, cytoplasmic 1 [Homo sapiens] immunoglobulin J chain precursor [Homo sapiens] lipocalin-1 isoform 1 precursor [Homo sapiens] alpha-amylase 1 precursor [Homo sapiens] zymogen granule protein 16 homolog B precursor [Homo sapiens] keratin, type I cytoskeletal 13 isoform a [Homo sapiens] kallikrein-1 preproprotein [Homo sapiens] transketolase isoform 1 [Homo sapiens]

BPI fold-containing family B member 2 precursor [Homo sapiens] glucose-6-phosphate isomerase isoform 1 [Homo sapiens] prolactin-inducible protein precursor [Homo sapiens] keratin, type I cytoskeletal 10 [Homo sapiens] carbonic anhydrase 6 isoform 1 precursor [Homo sapiens] keratin, type II cytoskeletal 4 [Homo sapiens] heat shock $70 \mathrm{kDa}$ protein $1 \mathrm{~A} / 1 \mathrm{~B}$ [Homo sapiens] serotransferrin precursor [Homo sapiens] lactoperoxidase isoform 1 preproprotein [Homo sapiens] zinc-alpha-2-glycoprotein precursor [Homo sapiens] deleted in malignant brain tumors 1 protein isoform c precursor [Homo... polymeric immunoglobulin receptor precursor [Homo sapiens] serum albumin preproprotein [Homo sapiens] mucin-5B precursor [Homo sapiens]

keratin, type I cytoskeletal 16 [Homo sapiens] macrophage migration inhibitory factor [Homo sapiens] aldehyde dehydrogenase, dimeric NADP-preferring [Homo sapiens] vitamin D-binding protein isoform 3 precursor [Homo sapiens] catalase [Homo sapiens] desmoglein-3 preproprotein [Homo sapiens] alpha-1-antitrypsin precursor [Homo sapiens] transaldolase [Homo sapiens] histone H3.2 [Homo sapiens] orm a precursor [Homo sapiens] gelsolin isoform d [Homo sapiens] 14-3-3 protein sigma [Homo sapiens] myeloperoxidase precursor [Homo sapiens] myeloblastin precursor [Homo sapiens] lysozyme $\mathrm{C}$ precursor [Homo sapiens] triosephosphate isomerase isoform 2 [Homo sapiens] alpha-actinin-1 isoform c [Homo sapiens] neutrophil elastase preproprotein [Homo sapiens] clusterin preproprotein [Homo sapiens] cystatin-C precursor [Homo sapiens] heat shock cognate $71 \mathrm{kDa}$ protein isoform 1 [Homo sapiens] matrix metalloproteinase-9 preproprotein [Homo sapiens] protein disulfide-isomerase precursor [Homo sapiens] protein S100-A9 [Homo sapiens]

haptoglobin isoform 2 preproprotein [Homo sapiens] BPI fold-containing family A member 2 precursor [Homo sapiens] alpha-enolase isoform 1 [Homo sapiens] annexin A1 [Homo sapiens]

6-phosphogluconate dehydrogenase, decarboxylating [Homo sapiens] BPI fold-containing family B member 1 precursor [Homo sapiens] alpha-2-macroglobulin-like protein 1 precursor [Homo sapiens] plastin-2 [Homo sapiens] lactotransferrin isoform 1 precursor [Homo sapiens]

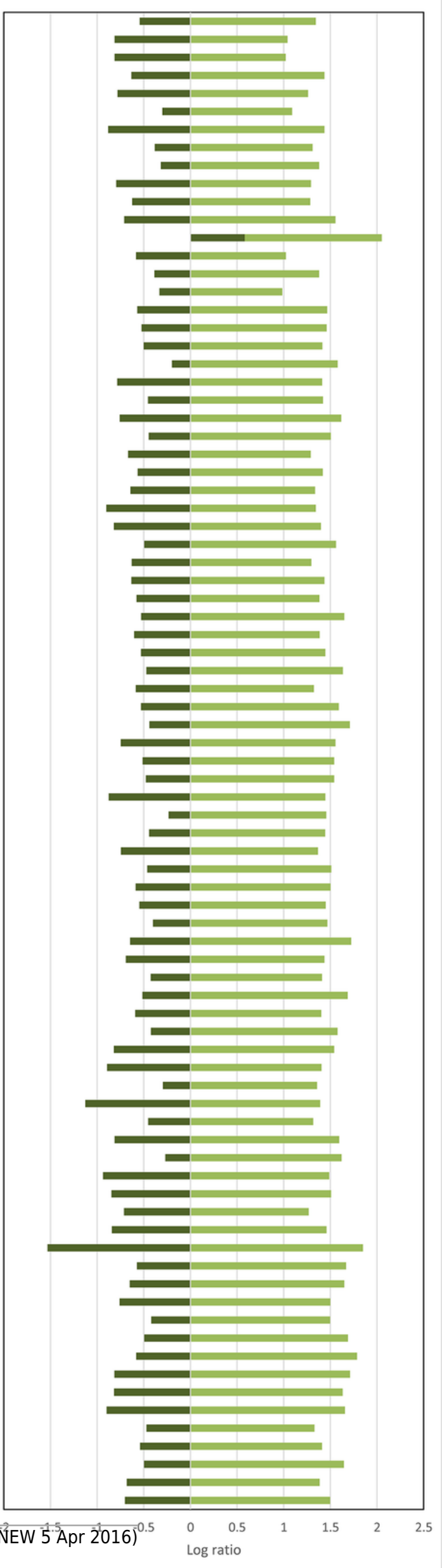


2

\section{Log ratio of relative intensity (NPDR/XDR; PDR/XDR or proteins found exclusively in NPDR and PDR disease groups.}

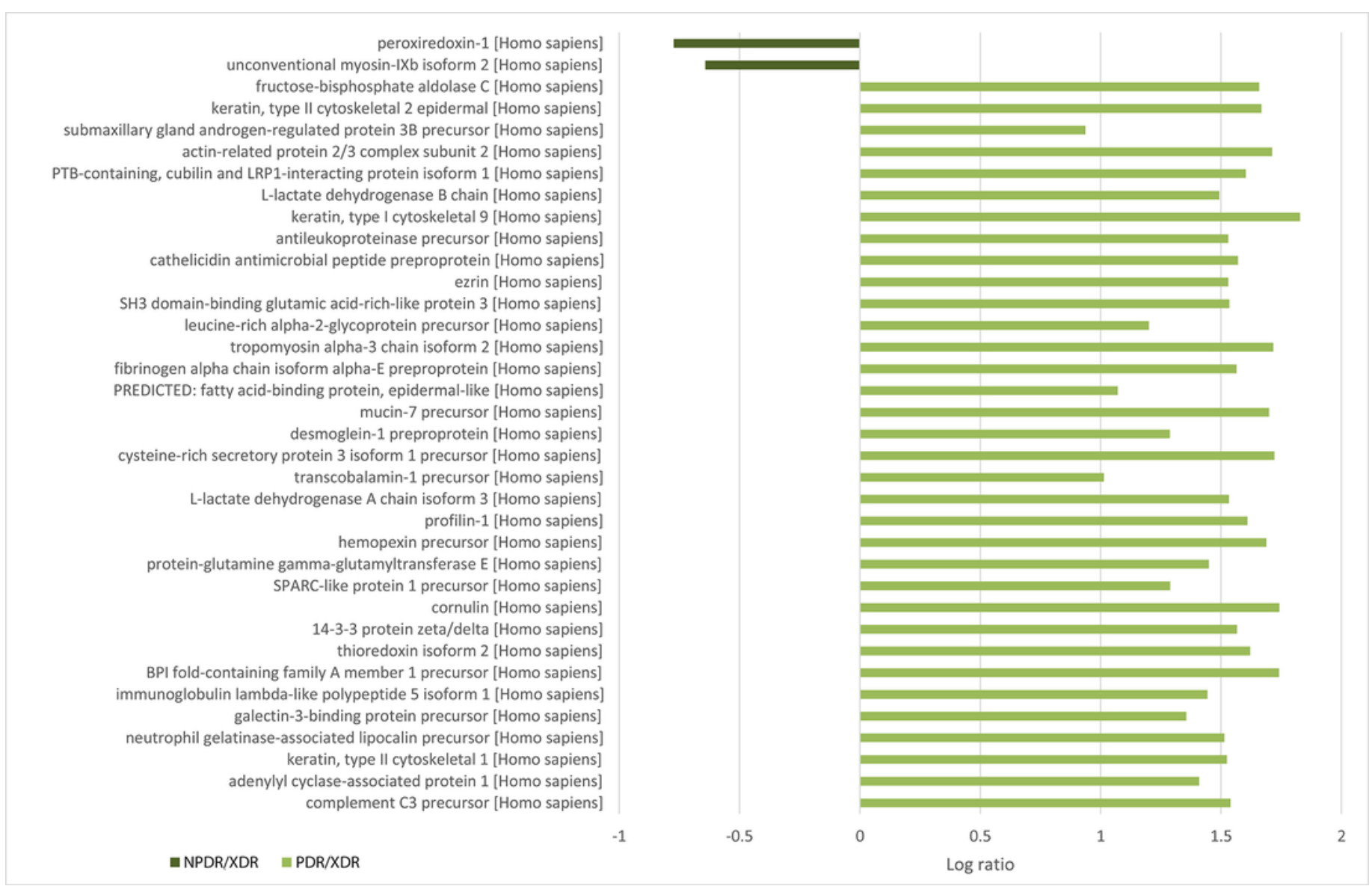


3

Canonical pathways comparative studies in differentially expressed proteins from NPDR and PDR groups. 


GNPDR/XDR G

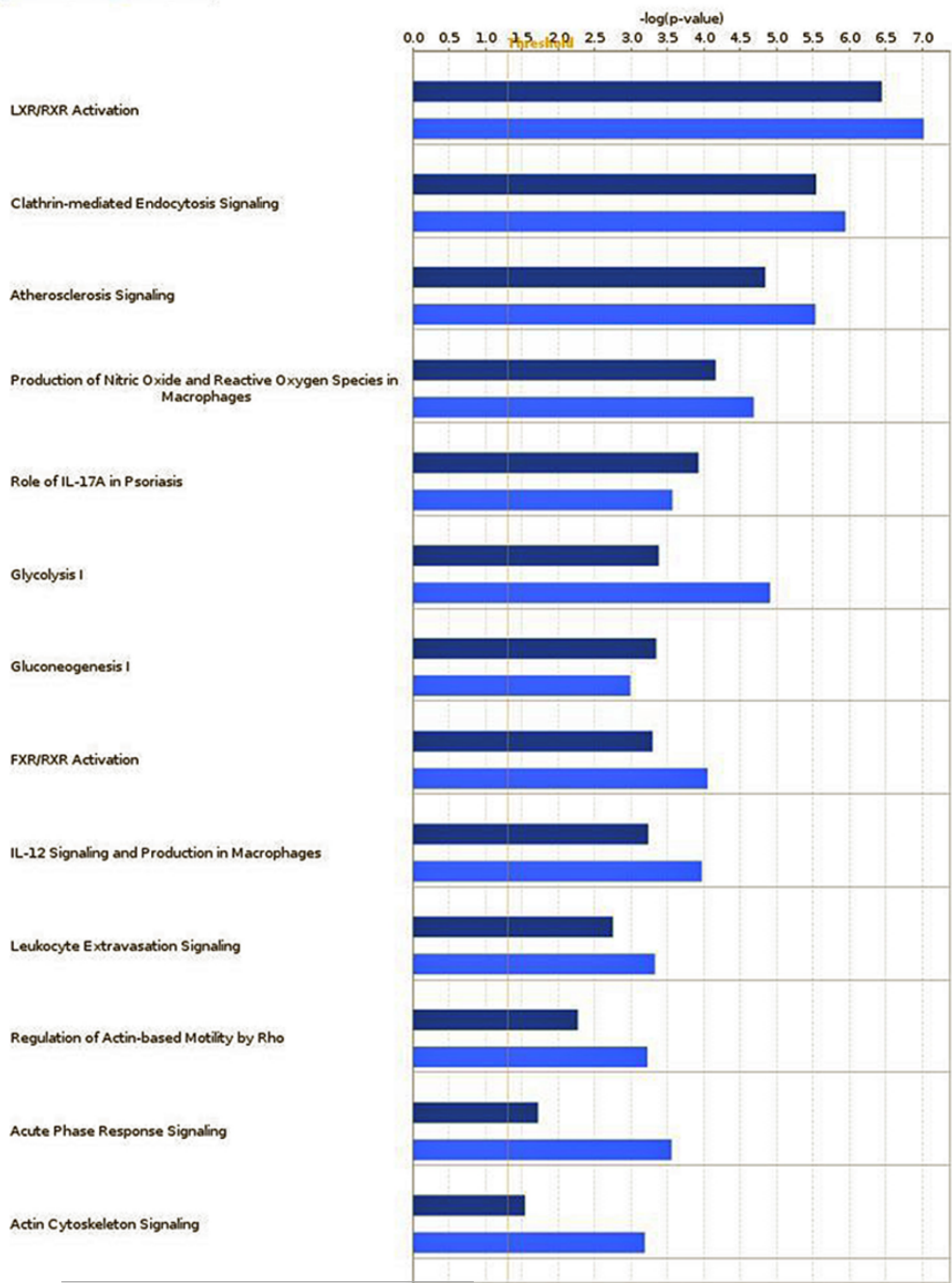


4

Summary of pathogenetic mechanism for non-proliferative diabetic retinopathy and proliferative diabetic retinopathy and the functional pathways involved. 


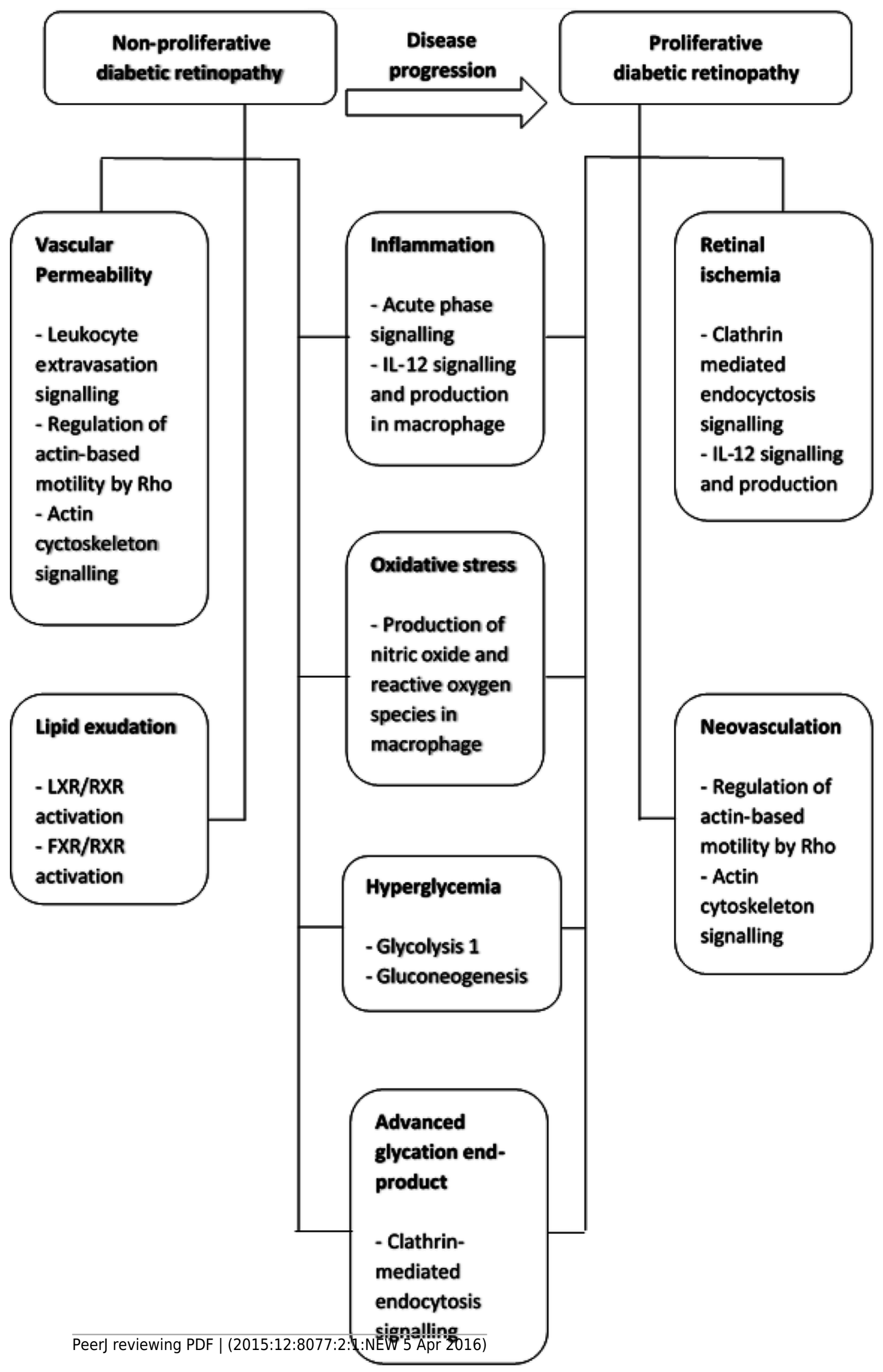

